\title{
Sizing the thermal energy storage (TES) device for organic Rankine cycle (ORC) power systems
}

\author{
Piotr Kolasiński ${ }^{1 *}$, and Sindu Daniarta ${ }^{1,2}$ \\ ${ }^{1}$ Department of Thermodynamics and Renewable Energy Sources, Wrocław University of Science \\ and Technology, Wybrzeże Wyspiańskiego 27, 50-370 Wrocław, Poland. \\ ${ }^{2}$ Department of Energy Engineering, Faculty of Mechanical Engineering, Budapest University of \\ Technology and Economics, Múegyetem rkp. 3, H-1111 Budapest, Hungary
}

\begin{abstract}
Thermal energy storage (TES) became one of the main research topics in modern power engineering. The design of TES devices and systems depend on their application. Different thermal energy storage materials (e.g., solids, liquids, or phase change materials) can be applied in TES devices. The selection of the thermal energy storage material depends mainly on the thermal power and operating temperature range of the TES device. These devices and systems are applied in different energy conversion systems, including solar power plants or combined heat and power (CHP) stations. The application of TES devices is also considered in the case of other industries, such as metallurgy. The possible application of TES devices is particularly promising in the case of organic Rankine cycle (ORC) systems. These systems are often utilizing floating heat sources such as solar energy, waste heat, etc. TES device can be therefore applied as the evaporator of the ORC system in order to stabilize these fluctuations. In this paper, the possible thermal energy storage materials used in TES devices applied in ORCs are discussed. Moreover, the modelling results are reported related to assessment parameters which can be applied to size the TES device for ORC system utilizing different low-boiling working fluids. The thermal properties of working fluids are taken from CoolProp. The function of heat capacity of different TES materials is also provided and the calculation is computed by employing MATLAB. The result shows that based on the simulation, the gradient of the natural characteristic of TES with working fluids $\left(\zeta\left(T_{\mathrm{b}}\right)\right)$ tends to decrease. The presented result in this paper gives a new point of view which can be used by scientists and engineers during the design and implementation of TES evaporators dedicated to ORC power systems.
\end{abstract}

\section{Introduction}

Intensive research aimed at methods and technologies which can be utilized by the modern power industry for environmental protection and efficiency improvement is currently proceeded. One of the most important challenges is still reducing fossil fuels consumption. Complete phase-out of fossil fuels is not possible in the case of many industrial processes (e.g., chemical factories, metallurgy, etc.), however, their negative impact can be limited in

\footnotetext{
* Corresponding author: piotr.kolasinski@pwr.edu.pl
} 
some processes by using renewable and waste energy sources, rationalization of energy management and increasing the energy conversion efficiency. Various forms of energy can be obtained from alternative sources, while thermal energy sources are particularly interesting in terms of their diversity and possible applications. Thermal energy can be easily converted into different energy products, such as electricity, cold or process heat thanks to the application of different power systems and technologies, for example, organic Rankine cycle (ORC) systems. The principle of ORC system operation is the same as in the case of standard steam power plant operating according to Clausius-Rankine cycle [1]. However, a low-boiling working fluid is used instead of water. Thanks to this change it is possible to extract the thermal energy from heat sources featuring lower thermal potential than in the case of standard steam power plants. ORCs currently became one of the most important research topics among energy conversion systems that can convert thermal energy from alternative energy sources. Practically, thermal energy is transferred by carriers that are characterized by different thermal potentials and physical forms. These include high temperature $\left(500-1500^{\circ} \mathrm{C}\right)$, medium temperature $\left(250-500{ }^{\circ} \mathrm{C}\right)$ and low temperature $(40-250$ ${ }^{\circ} \mathrm{C}$ ) renewable and waste heat carriers. The temperature level of the heat carrier and its output are defining the exergy level and power of the heat source, and thus its quality and suitability for an application. The high- and medium-temperature carriers are featuring the highest quality, while the quality of low-temperature carriers is lower. High- and mediumtemperature waste heat carriers are released in large industrial plants and factories [2], while renewable carriers featuring such thermal potential are limited to seismically active areas [3]. Concentrated solar power can also feature this level of temperature [4]. In the industry, various technologies such as waste heat recovery boilers and steam power plants are applied to harvest the heat contained in high- and medium-temperature waste heat carriers [5]. The recovered energy can be then used to cover the own needs of technological processes, (e.g., process steam production in recovery boilers, heating of combustion substrates, drying processes) or can be applied to generate electricity, heat or cold. Unlike high- and mediumtemperature carriers, low-temperature renewable and waste carriers are common and spatially dispersed and are rarely used, mainly due to the limited availability of efficient recovery technologies. What is more, low-temperature renewable and waste carriers are often featuring fluctuating thermal and output characteristics which can negatively influence the operating conditions of the recovery system.

Thermal energy storage (TES) systems and devices can potentially be applied to balance the fluctuating heat source. TES devices can differ in terms of the design and applied storage substance. Different solids and liquids featuring high thermal capacity, as well as phase change substances (i.e., PCM - phase change materials) can be applied in TES devices. Applied storage substances should also be chemically stable and resistant to cyclical processes of charging and discharging. The applied solids are, for example, rocks (granite or soapstone), reinforced concrete, cast iron, cast steel, as well as silica and magnesite refractory bricks. The liquids used are water, organic liquids and various types of oils (including hardening oils). Applied PCM's are organic, inorganic and eutectic substances (such as hydrated salts, paraffin, etc.). Thanks to the beneficial effect of latent heat release during a phase transition use of PCM's as storage substances results in higher efficiency and performance of the TES device. Basic technical parameters (i.e., operating temperature range, heat capacity, power, efficiency, storage period and investment cost) of the TES device depend on its type and storage substance used. The operating temperature of TES devices ranges from 200 to $1200^{\circ} \mathrm{C}$ (solid accumulating substances), $20-260^{\circ} \mathrm{C}$ (liquid accumulating substances) and $20-120^{\circ} \mathrm{C}$ (PCM's) [6]. Single TES devices can be combined into a larger TES system which can be charged by various heat sources (i.e., conventional as well as renewable and waste). Depending on the type of TES, heat can be stored for a different period of time, starting from several hours (short-term storage) up to several months (long-term 
storage). The most important properties of TES devices are heat capacity, power, performance, charging and discharging times, and investment costs. The design and principle of operation of the TES device may be similar to the design of regenerators or classic shell and tube heat exchangers. The difference is that the heat is transferred from the heat carrier to the storage substance instead of the second working fluid. The comparison of the temperature range of heat sources utilized by ORC systems with the operating temperatures of different types of TES devices shows that TES devices using solids and liquids as heat accumulating substances are the most promising to be applied in ORC systems. The application of PCM-based TES devices may be limited in ORC due to the low operating temperature range (up to ca. $120^{\circ} \mathrm{C}$ ). The TES device investment costs depend on its design, operating parameters, storage material used and the place of application. These costs vary between 10-100 EUR/kWh [7].

The most important technical data related to different types of TES devices [7,8] are reported in Table 1. By the type of storage substance used, TES devices can be divided into types listed in Table 2 [7-11].

One of the possible applications of TES devices in ORCs can be the use of a TES device instead of an evaporator (or as an additional heat exchanging device). Such an application of the TES device gives the opportunity for balancing the fluctuating heat source (such as solar radiation, heat obtained from biomass combustion, geysers, etc.). In the literature studies, some articles have reported the TES device instead of an evaporator for ORC power systems $[7,12]$. Many configurations of TES in ORC presented in the articles, however, there is still few data concerning the modelling. Therefore, in the following part of the paper, the results of modelling of the size of the TES device which is considered to be applied as the main heat source for the ORC system are presented for different low-boiling working fluids, storage materials and operating temperature ranges. This paper also shows the gradient of sizing as a function of outlet temperature before the expansion process.

Table 1. Classification of TES devices by the physical phenomenon being the principle of TES device operation $[7,8]$.

\begin{tabular}{|c|c|c|}
\hline Phenomena & Heat type & Storage medium \\
\hline \multirow[b]{2}{*}{ Thermal phenomena } & Sensible heat & $\begin{array}{l}\text { Liquids } \\
\text { Solids }\end{array}$ \\
\hline & Latent heat & $\begin{array}{l}\text { Solid-liquid } \\
\text { Liquid-gas } \\
\text { Solid-solid }\end{array}$ \\
\hline \multirow{3}{*}{ Chemical phenomena } & $\begin{array}{c}\text { Thermal chemical } \\
\text { pipeline }\end{array}$ & - \\
\hline & $\begin{array}{c}\text { The heat of chemical } \\
\text { reaction }\end{array}$ & - \\
\hline & Chemical heat pumps & - \\
\hline
\end{tabular}


Table 2. Typical parameters of TES devices [7-11].

\begin{tabular}{|c|c|c|c|c|c|c|}
\hline $\begin{array}{c}\text { Type of } \\
\text { device }\end{array}$ & $\begin{array}{c}\text { Thermal } \\
\text { capacity } \\
\mathbf{( k W h / t )}\end{array}$ & $\begin{array}{c}\text { Temperature } \\
\text { range }\left({ }^{\circ} \mathbf{C}\right)\end{array}$ & $\begin{array}{c}\text { Power } \\
\mathbf{( M W )}\end{array}$ & $\begin{array}{c}\text { Efficiency } \\
\mathbf{( \% )}\end{array}$ & $\begin{array}{c}\text { Storage } \\
\text { period }\end{array}$ & $\begin{array}{c}\text { Cost } \\
(\mathbf{E U R} / \mathbf{k W})\end{array}$ \\
\hline $\begin{array}{c}\text { Sensible (hot } \\
\text { water) }\end{array}$ & $10-50$ & $40-100$ & $\begin{array}{c}0.001- \\
10.0\end{array}$ & $50-90$ & Days/months & $0.1-10$ \\
\hline $\begin{array}{c}\text { Phase-change } \\
\text { material } \\
\text { (PCM) }\end{array}$ & $50-150$ & $40-220$ & $\begin{array}{c}0.001- \\
1.0\end{array}$ & $75-90$ & Hours/months & $10-50$ \\
\hline $\begin{array}{c}\text { Chemical } \\
\text { reactions }\end{array}$ & $120-250$ & $400-1200$ & $0.01-$ & $75-100$ & Hours/days & $8-100$ \\
\hline
\end{tabular}

\section{Systems, models and mathematical description}

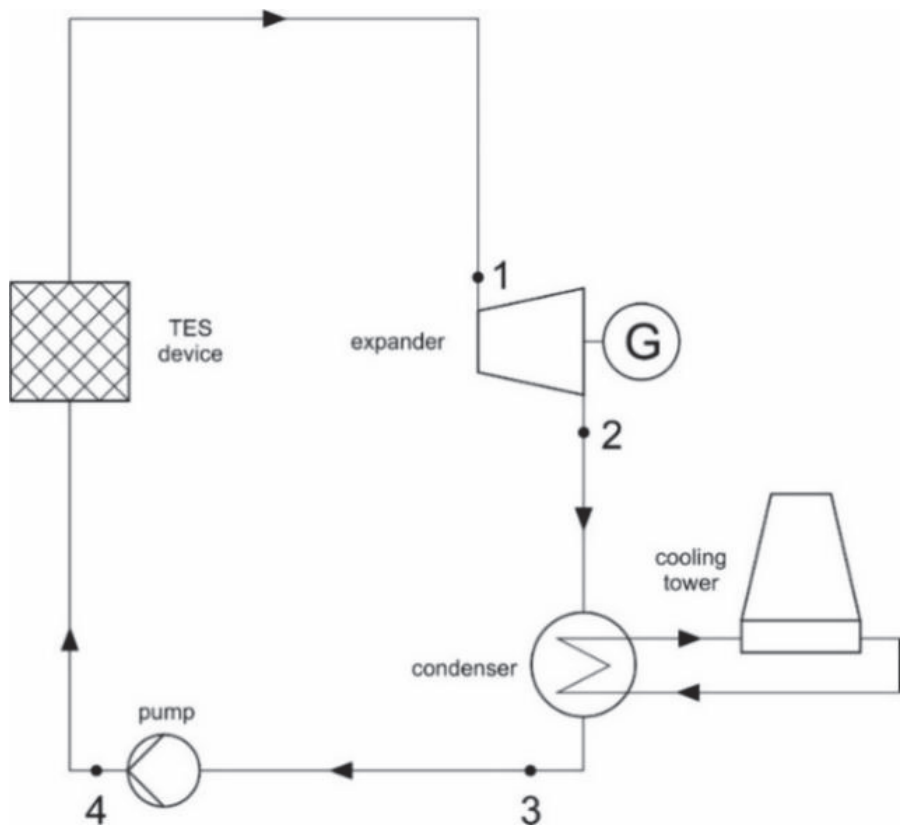

Fig. 1. Schematic layout of the ORC system with TES device [12].

Figure 1 shows the scheme of the modelled system. TES device is applied in the system as the heat supply. In the real ORC system, thanks to such an application of TES device it would be possible to supply the heat to the system continuously in case of powering the system via heat sources featuring floating thermal and output characteristics (e.g., solar thermal energy). The ORC system is therefore composed of a TES device, expander, condenser and pump. A low-boiling working fluid flow is forced by a pump to the inlet of the TES device where it evaporates. Obtained vapour flows via pipelines to the inlet of the expander (turbine or volumetric machine) where during expansion its thermal parameters are reduced and thermal energy is converted into mechanical energy of the expander's rotating shaft. After expansion, working fluid is flowing through the pipelines to the inlet of the condenser, where it rejects heat to the cooling fluid and is liquified. The obtained liquid is then directed again to the 
pump and the working cycle therefore completes. Figure 2 shows the $T$-s diagram of the ORC cycle (red lines). Shaded regions in Figure 2 visualize the heat needed for working fluid preheating, evaporation and superheating.

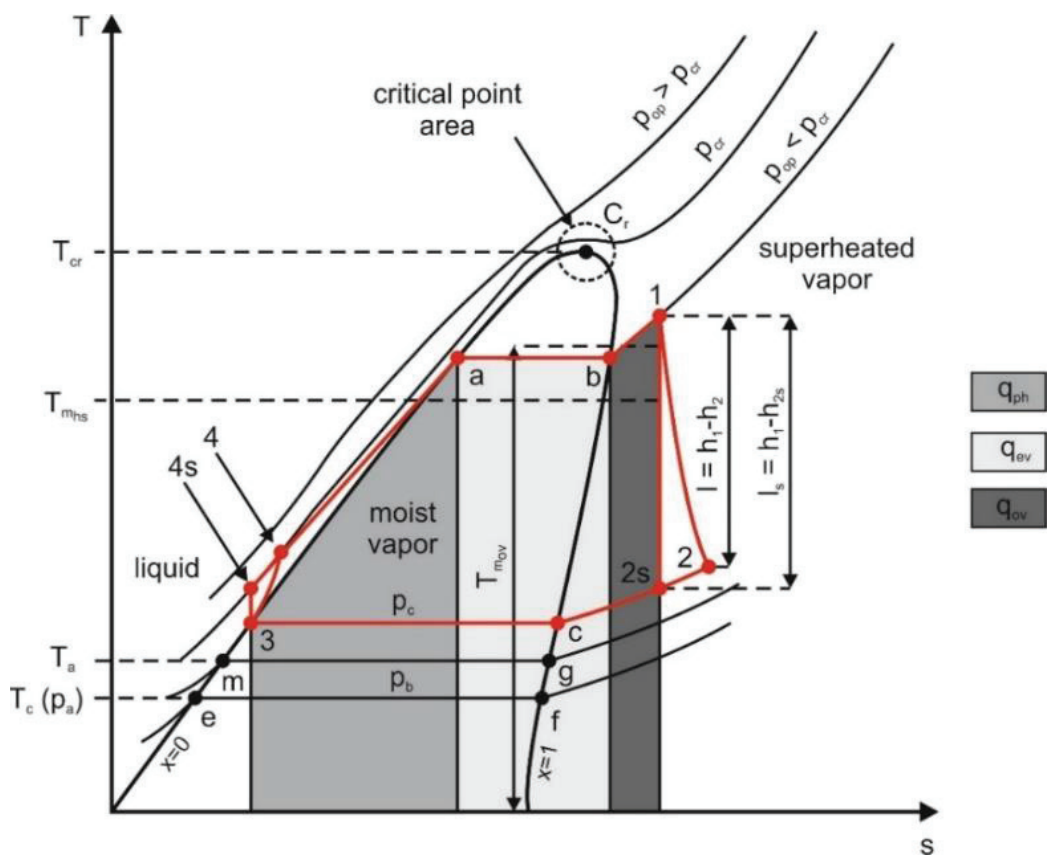

Fig. 2. $T$-s diagram of the ORC cycle (red lines). Shaded regions visualize the heat needed for working fluid preheating $\left(q_{\mathrm{ph}}\right)$, evaporation $\left(q_{\mathrm{ev}}\right)$ and superheating $\left(q_{\mathrm{ov}}\right)$ [12].

Different low-boiling working fluids and different thermal storage substances can be applied in the considered system. The working fluid selection can be based on different selection criteria. The most important are the environmental impact of the substance (i.e., ODP and GWP), safety (e.g., toxicity, flammability and explosivity) and thermal properties. It is of great importance that working fluid should be safe both for the environment and humans. The list of working fluids that can be applied in ORCs was significantly limited by international regulations and many of the working fluids which were successfully applied in ORCs (e.g., R11 and R123) are currently banned or being withdrawn from the application. Therefore, in the present study, we decided to consider these working fluids which negative impact on the environment is significantly limited. The list of considered working fluids is reported in Table 3. Taking into account the thermal properties of the selected fluids we decided to limit the treatment to the subcritical cycles, therefore the modelling is proceeded for the TES device temperature ranging from $373.15 \leq T_{\text {upper }} \leq T_{\text {crit }}-20 \mathrm{~K}$ (see Table 3 ). For these conditions of the heat source the heat amount needed to preheat and evaporate the working fluid (per $1 \mathrm{~kg}$ of substance) can vary for different working fluids and could be calculated using Equations (1) and (2).

$$
\begin{aligned}
& q_{\text {pre }}=h_{\mathrm{a}}-h_{4} \\
& q_{\mathrm{ev}}=h_{\mathrm{a}}-h_{\mathrm{b}}
\end{aligned}
$$

The thermal energy of the TES device can be calculated using the following Equation (3). 


$$
Q_{\mathrm{TES}}=m_{\mathrm{sm}} \cdot c_{\mathrm{psm}} \cdot T_{\mathrm{sm}}
$$

Where $m_{\mathrm{sm}}$ is the mass of the heat storage material, $c_{\mathrm{psm}}$ is the specific heat capacity of storage material, $T_{\mathrm{sm}}$ is the temperature of storage material.

Table 3. The thermal properties of the considered low-boiling working fluids taken from CoolProp [13], the boundary condition and the steps of calculation.

\begin{tabular}{|c|c|c|c|c|c|c|c|c|}
\hline No & $\begin{array}{c}\text { The selected } \\
\text { working fluid }\end{array}$ & CAS no. & $\begin{array}{c}T_{\text {crit }} \\
\text { (K) }\end{array}$ & $\begin{array}{c}T_{\text {triple }} \\
\text { (K) }\end{array}$ & $\begin{array}{c}T_{\text {boiling }} \\
\text { (K) }\end{array}$ & $\begin{array}{c}T_{\text {lower }} \\
(\mathbf{K}) \\
\end{array}$ & $\begin{array}{l}T_{\text {upper }} \\
\text { (K) }\end{array}$ & $\begin{array}{c}\text { Steps } \\
(\mathbf{K})\end{array}$ \\
\hline 1 & Butane & $106-97-8$ & 425.12 & 134.89 & 272.66 & 308.00 & \multirow{9}{*}{ 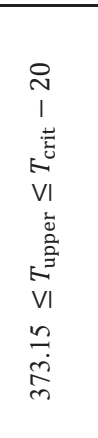 } & 0.01 \\
\hline 2 & Diethyl ether & $60-29-7$ & 466.70 & 27000 & 307.60 & 308.00 & & 0.01 \\
\hline 3 & Isohexane & $107-83-5$ & 497.70 & 119.60 & 333.36 & $T_{\text {boiling }}+10$ & & 0.01 \\
\hline 4 & Neopentane & $463-82-1$ & 433.74 & 256.60 & 282.65 & 308.00 & & 0.01 \\
\hline 5 & Novec 649 & $756-13-8$ & 441.81 & 165.00 & 322.20 & $T_{\text {boiling }}+10$ & & 0.01 \\
\hline 6 & Pentane & 109-66-0 & 469.70 & 143.47 & $319.20^{*}$ & $T_{\text {boiling }}+10$ & & 0.01 \\
\hline 7 & R1233zd(E) & $102687-65-0$ & 439.60 & 195.15 & 291.41 & $T_{\text {boiling }}+10$ & & 0.01 \\
\hline 8 & R245ca & $679-86-7$ & 447.57 & 196.00 & 298.41 & $T_{\text {boiling }}+10$ & & 0.01 \\
\hline 9 & R365mfc & $406-58-6$ & 460.00 & 239.00 & 313.34 & $T_{\text {boiling }}+10$ & & 0.01 \\
\hline
\end{tabular}

${ }^{*}$ The boiling temperature at the pressure of $140,805 \mathrm{~Pa}$.

The heat that can be extracted from the TES device during its cooling from its initial temperature of $T_{\mathrm{A}}$ to the final temperature $T_{\mathrm{B}}$ can be calculated using Equation (4).

$$
\Delta Q_{\mathrm{TES}}=m_{\mathrm{sm}} \cdot c_{\mathrm{psm}} \cdot\left(T_{\mathrm{A}}-T_{\mathrm{B}}\right)
$$

In this study, we decided to omit the analyses related to superheating of the working fluid as this process is not often applied in practice and for many working fluids its application leads to lowered cycle efficiency $[14,15]$. On the basis of the selected temperature of the TES device the range of TES operating temperature was selected as reported in Table 4. As it was mentioned earlier TES devices can use different solids, liquids and PCMs as storage materials. In this study, we focus on the TES device temperatures higher than $100{ }^{\circ} \mathrm{C}$. Therefore, PCMs were not included in the present study, and the focus was paid to selected solids and liquids which were reported by different authors as promising materials for thermal energy storage. The list of these materials is reported in Table 4.

To size a thermal storage device, it is possible to define an assessment parameter using which it is possible to calculate the mass of thermal storage material which is needed to store a certain quantity of heat and on this basis compare different thermal energy storage materials and ORC working fluids. The other, below defined, assessment parameters can be useful for making the comparison of the different TES devices which are applied in ORC power systems that utilize different working fluids.

The specific heat capacity of thermal energy storage materials is not constant and is more or less dependent on temperature. High variability of this parameter is especially visible during phase transitions. Specific heat capacity of material can be determined experimentally (for example differential scanning calorimetry/DSC can be applied for this purpose). The obtained experimental results are then approximated by polynomial equations. The general polynomial equation for the specific heat capacity of a material can be given as Equation (5), the selected TES material is given in Table 4. 


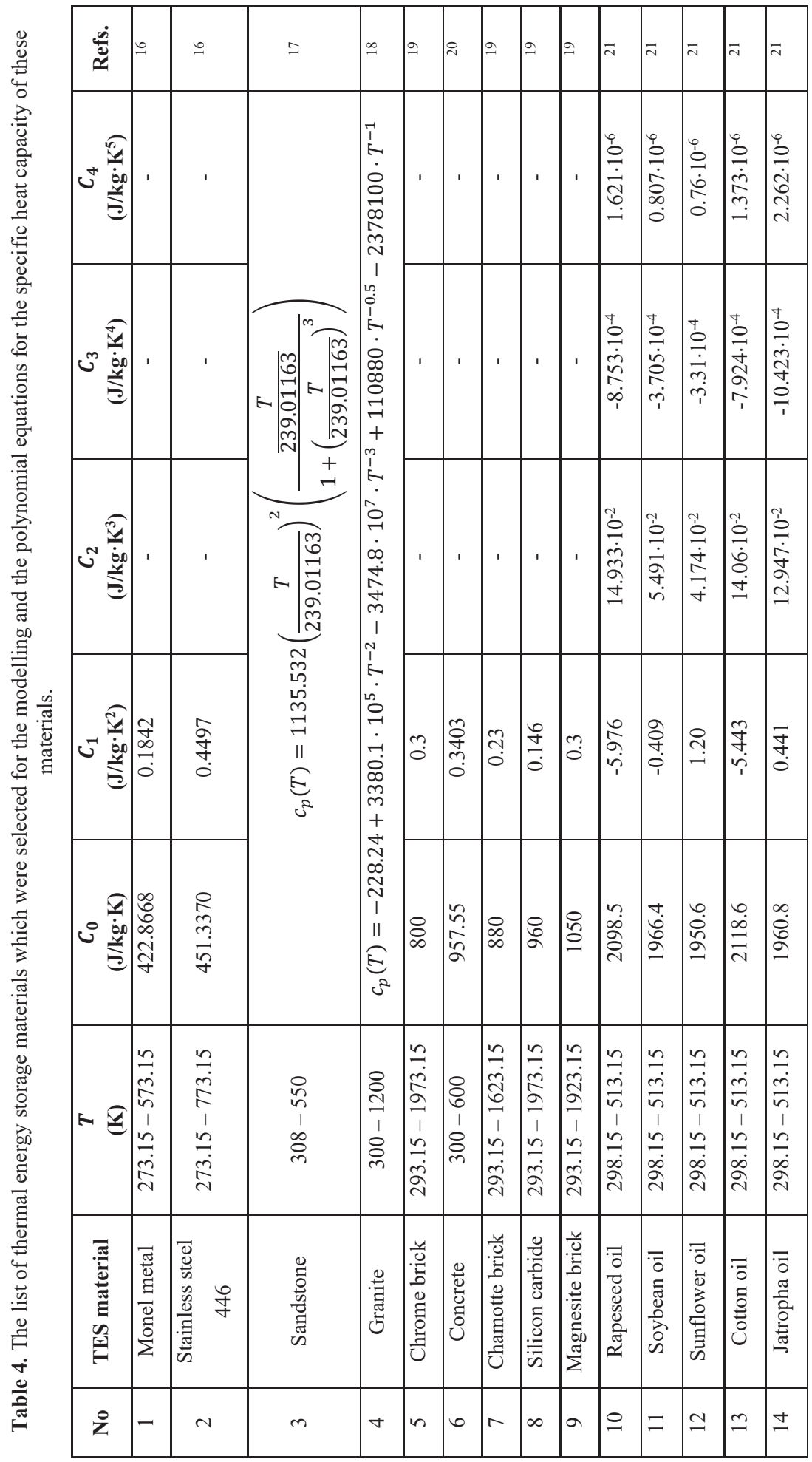




$$
c_{\mathrm{p}}(T)=C_{0}+C_{1} T+C_{2} T^{2}+C_{3} T^{3}+\cdots+C_{\mathrm{n}} T^{\mathrm{n}}
$$

where $C_{0} \ldots C_{\mathrm{n}}$ are polynomial approximation constants and $T$ is the temperature.

Table 4 reports the polynomial equations for the specific heat capacity of thermal energy storage materials which were selected for the modelling. The heat transfer process can be treated as isobaric. Therefore, the mass and enthalpy change of thermal energy storage material needed to proceed with the preheating, evaporation and superheating of the $1 \mathrm{~kg}$ of low-boiling working fluid can be obtained from the following energy balance of TES device, Equation (6).

$$
m_{\mathrm{WF}} \cdot\left(h_{1}-h_{4}\right)=m_{\mathrm{sm}} \cdot c_{\mathrm{p}}\left(T_{\mathrm{sm}}\right) \cdot\left(T_{\mathrm{TES} 1}-T_{\mathrm{TES} 2}\right)
$$

where $T_{\mathrm{TES} 1}$ and $T_{\mathrm{TES} 2}$ are the initial and the final temperature of the TES device.

Therefore, the dimensionless storage mass parameter as an assessment that can be applied for sizing the thermal energy storage device used to preheat, evaporate and superheat $1 \mathrm{~kg}$ of low-boiling working fluid can be calculated by Equation (7).

$$
\zeta_{\mathrm{sm}}=\frac{m_{\mathrm{sm}}}{m_{\mathrm{WF}}}=\frac{h_{1}-h_{4}}{\left.c_{\mathrm{p}}\left(T_{S m}\right)\right|_{T_{\mathrm{TES} 1}} ^{T_{\mathrm{TES} 2}} \cdot\left(T_{\mathrm{TES} 1}-T_{\mathrm{TES} 2}\right)}
$$

where $m_{\mathrm{WF}}$ is the mass of the low-boiling working fluid (in the present study it is assumed as $m_{\mathrm{WF}}=1 \mathrm{~kg}$ ). Furthermore, the value of $m_{\mathrm{sm}}$ (which is the mass of the heat storage material) can be determined from the result of dimensionless storage mass parameter from the ratio of enthalpy changes.

As mentioned above, in the present study we treat the ORC cycle as evaporation (superheating is not considered). Therefore, in this modelling the dimensionless storage mass parameter is calculated by Equation (8).

$$
\zeta_{s m}=\frac{m_{\mathrm{sm}}}{m_{\mathrm{WF}}}=\frac{h_{\mathrm{b}}-h_{4}}{\left.c_{\mathrm{p}}\left(T_{s m}\right)\right|_{T_{\mathrm{TES} 1}} ^{T_{\mathrm{TES} 2}} \cdot\left(T_{\mathrm{TES} 1}-T_{\mathrm{TES} 2}\right)}
$$

\section{Results and discussion}

The obtained modelling results related to the variation of the dimensionless storage mass parameter $\zeta$ vs. temperature of the working fluid at the outlet of the TES device $\left(T_{\mathrm{b}}\right)$ are summarized in Figure 3 for different working fluids and different solids used as the thermal energy storage materials. The analysis of the modelling results presented in Figure 3 gives the possibility to compare and estimate the size of the TES device. The value of $\zeta\left(T_{\mathrm{b}}\right)$ parameter gives the information about the mass of thermal energy storage material which is needed to preheat and evaporate $1 \mathrm{~kg}$ of low-boiling working fluid. Therefore, the lower the value of this parameter is, the smaller mass of thermal energy storage material will be needed to evaporate the working fluid. The obtained values of $\zeta\left(T_{\mathrm{b}}\right)$ parameter ranges between 1.09 and 22.19. The highest value of this parameter is obtained for Monel metal and neopentane for the TES device temperature of $T_{\mathrm{b}}=360 \mathrm{~K}$. Obtained modelling results can be discussed on the examples enlarged in Figure 3. For example, if butane is selected as the working fluid, the obtained values of the $\zeta\left(T_{\mathrm{b}}\right)$ parameter ranges between 2.98 and 12.16 for different thermal energy storage materials. The lowest values of this parameter are obtained for granite, while the highest values are obtained for Monel metal. The variation of the $\zeta\left(T_{\mathrm{b}}\right)$ parameter calculated for selected thermal energy storage material and different working 


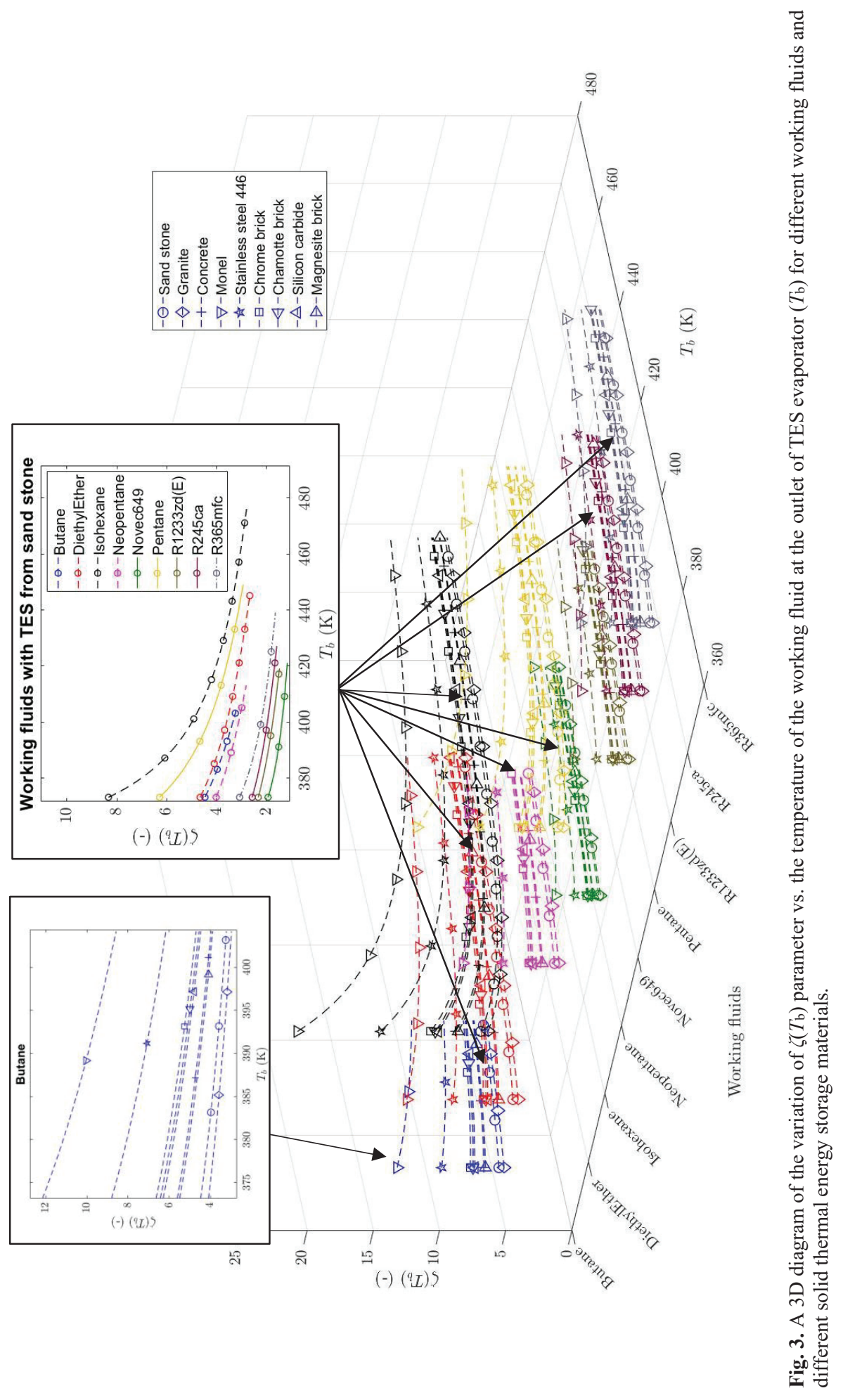




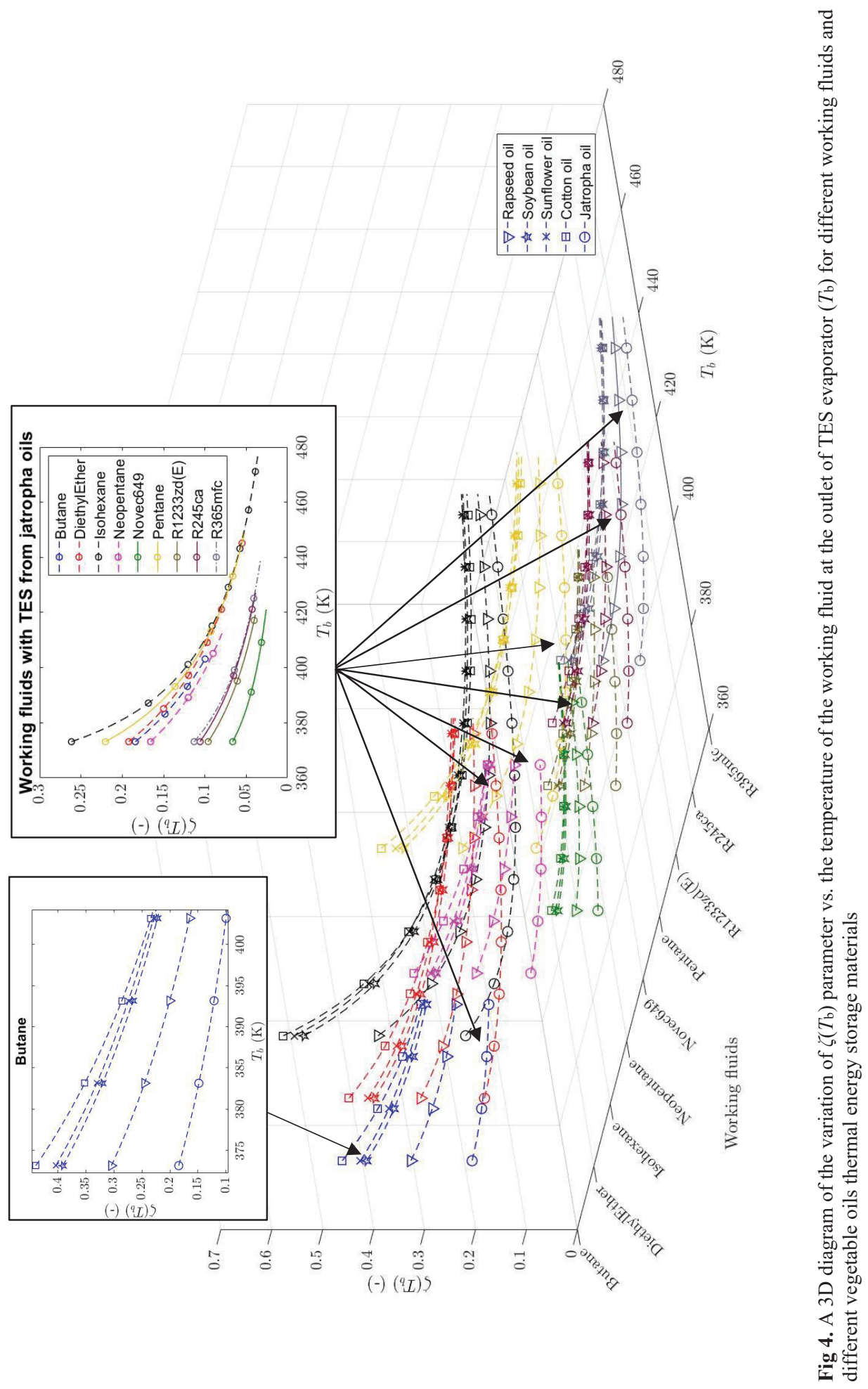


fluids can be discussed based on the sandstone as it is enlarged in Figure 3. The obtained values of the $\zeta\left(T_{\mathrm{b}}\right)$ parameter ranges between 1.17 and 8.34 for different working fluids and TES device temperature range. The lowest values of this parameter are found for Novec649, while the highest values are obtained for isohexane. Therefore, for the TES device utilizing sandstone Novec639 seems to be the working fluid which application gives the possibility of limiting the size and mass of the TES device if the maximum temperature of the working fluid at the outlet of the TES device is $T_{\mathrm{b}}=420 \mathrm{~K}$. If the higher temperature of the working fluid at the outlet of TES device is considered R $245 \mathrm{ca}, \mathrm{R} 365 \mathrm{mfc}$, diethyl ether, pentane and isohexane are the working fluids for which the $\zeta\left(T_{\mathrm{b}}\right)$ parameter ranges between 2 and 5 .

The TES material using vegetables are separately drawn which can be seen in Figure 4. Generally, since the heat capacity of these vegetable liquids is high, the sizing using these vegetable liquids are relatively smaller than the selected rocks and metals.

Figure 4 visualizes the variation of the dimensionless storage mass parameter $\zeta$ vs. temperature of the working fluid at the outlet of the TES device $\left(T_{\mathrm{b}}\right)$ for different working fluids and different vegetable liquids (i.e., oils) used as the thermal energy storage materials. For these thermal energy storage materials, the obtained values of $\zeta\left(T_{\mathrm{b}}\right)$ parameter ranges between 0.01 and 0.62 . The lowest values of this parameter are obtained for Novec639 and jatropha oil, while the highest values are obtained for isohexane and cotton oil. Therefore, for the TES device temperature ranging between $370 \mathrm{~K}$ and $420 \mathrm{~K}$ selection of Novec 639 as ORC working fluid and jatropha oil as thermal energy storage material can give the opportunity of limiting the size and mass of the TES device. If the higher temperature of the working fluid at the outlet of the TES device is considered R365mfc with jatropha oil, $\mathrm{R} 365 \mathrm{mfc}$ with rapeseed oil, pentane with jatropha oil, and isohexane with jatropha oil are the pairs of ORC working fluids and thermal energy storage materials for which the $\zeta\left(T_{\mathrm{b}}\right)$ parameter ranges between 0.02 and 0.07 .

In this study, if the simulation is calculated separately by increasing the evaporation temperature, the enthalpy change of evaporator gradually drops while the enthalpy change of preheater is gradually rising (this phenomenon occurs as an effect of the boundary condition based on the saturated curve). It is found that the enthalpy changes of the combined evaporator, preheater and TES slightly rise. Furthermore, the specific heat capacity of the selected TES materials significantly increases. By knowing these conditions, the result shows that the dimensionless storage mass parameters tend to decline in Figure 3 and 4.

\section{Conclusions}

This paper has presented the results of the analysis on sizing the TES evaporator for ORC systems and its gradient as a function of temperature before the expansion process. Thermal energy storage devices are especially promising for powering the ORC systems utilizing the heat sources with floating output and temperature characteristics, such as waste or solar heat. The dimensionless storage mass parameter which can be used for sizing the TES evaporator for the ORC system was defined and introduced. This parameter can be applied for assessing the applicability of different thermal energy storage materials for different organic working fluids and sizing TES devices. The modelling results show that depending on the temperature of the working fluid at the outlet of the TES device and applied working fluid the value of the dimensionless storage mass parameter may vary in the range between 1 and 20 and differs for different working fluids and thermal energy storage materials. The obtained modelling results show that Novec396 seems to be a promising working fluid for applications in which the temperature of the working fluid at the outlet of the TES evaporator is limited to $T_{\mathrm{b}}=420$ $\mathrm{K}$, while R245ca, R365mfc, pentane and isohexane are the working fluids which application can be promising in case of higher temperature of the working fluid at the outlet of TES 
evaporator. Among the considered thermal energy storage materials, results of modelling related to granite and liquid oils give promising, low values of dimensionless storage mass parameters.

The analysis presented in this paper gives the results which can be used by scientists and engineers during the design and implementation of TES evaporators dedicated to ORC systems.

\section{References}

1. T. Zygmunt Kaczmarczyk, Energy Convers. Manag. 244, 114437 (2021).

2. H. Jouhara, N. Khordehgah, S. Almahmoud, B. Delpech, A. Chauhan, and S.A. Tassou, Therm. Sci. Eng. Prog. (2018).

3. M.H. Dickson and M. Fanelli, Geothermal Energy: Utilization and Technology (Routledge, 2013).

4. H.L. Zhang, J. Baeyens, J. Degrève, and G. Cacères, Renew. Sustain. Energy Rev. 22, $466(2013)$.

5. P. Kolasiński and B. Rogosz, in 32nd Int. Conf. Effic. Cost, Optim. Simul. Environ. Impact Energy Syst. ECOS 2019, edited by S. W., G. P., W. S., and A. W. (Institute of Thermal Technology, Department of Thermodynamics, Theory of Machines and Thermal Systems, Wrocław University of Science and Technology, Wrocław, Poland, 2019), pp. 4607-4617.

6. A. Sharma, V. V Tyagi, C.R. Chen, and D. Buddhi, Renew. Sustain. Energy Rev. 13, 318 (2009).

7. P. Kolasiński, Therm. Sci. Eng. Prog. 19, 100586 (2020).

8. I. Sarbu and C. Sebarchievici, Sustain. 10, (2018).

9. S. Ushak, A.G. Fernández, and M. Grageda, in Woodhead Publ. Ser. Energy, edited by L.F.B.T.-A. in T.E.S.S. Cabeza (Woodhead Publishing, 2015), pp. 49-63.

10. S.C. Johnson, F. Todd Davidson, J.D. Rhodes, J.L. Coleman, S.M. Bragg-Sitton, E.J. Dufek, and M.E. Webber, in edited by H. Bindra and S.B.T.-S. and H. of N.E. Revankar (Academic Press, 2019), pp. 119-175.

11. L. André, S. Abanades, and G. Flamant, Renew. Sustain. Energy Rev. 64, 703 (2016).

12. P. Kolasiński, Układy Organic Rankine Cycle (ORC) Małej i Średniej Mocy Wykorzystujące Rozprężarki Wyporowe (Oficyna Wydawnicza Politechniki Wroclawskiej, Wrocław, 2021).

13. I.H. Bell, J. Wronski, S. Quoilin, and V. Lemort, Ind. Eng. Chem. Res. 53, 2498 (2014).

14. G. Qiu, Renew. Energy 48, 565 (2012).

15. T. Yamamoto, T. Furuhata, N. Arai, and K. Mori, Energy 26, 239 (2001).

16. T.B. Douglas and J.L. Dever, J. Res. Natl. Bur. Stand. (1934). 54, 15 (1955).

17. I.M. Abdulagaov, Z.Z. Abdulagatova, S.N. Kallaev, and Z.M. Omarov, Geomech. Geophys. Geo-Energy Geo-Resources 5, 65 (2019).

18. S.Q. Miao, H.P. Li, and G. Chen, J. Therm. Anal. Calorim. 115, 1057 (2014).

19. E. Kostowski, Przeptyw Ciepła (Wydawnictwo Politechniki Śląskiej, Gliwice, 2010).

20. J. Pan, R. Zou, and F. Jin, Energies 10, (2017).

21. J.-F. Hoffmann, G. Vaitilingom, J.-F. Henry, M. Chirtoc, R. Olives, V. Goetz, and X. Py, Sol. Energy Mater. Sol. Cells 178, 129 (2018). 